\title{
Psoriasis and Metabolic Syndrome
}

\author{
Eldina Malkic Salihbegovic ${ }^{1}$, Nermina Hadzigrahic ${ }^{2}$, Amra Jakubovic Cickusic ${ }^{2}$
}

\author{
${ }^{1}$ Health Center Zivinice, Zivinice, Bosnia and Herzegovina \\ ${ }^{2}$ University Clinical Center Tuzla, Tuzla, Bosnia and Herzegovina
}

Corresponding author: Eldina Malkic Salihbegovic, MD.. Health Center Zivinice, Alije Izetbegovica 17, 75270 Zivinice, Bosnia and Herzegovina. Phone: +38761650733; E-mail: elmasa976@yahoo.com.

\begin{abstract}
Introduction: Psoriasis is a chronic skin ailment which can be connected with an increased occurrence of other illnesses, including the metabolic syndrome. Examinees and methods: A prospective study has been conducted which included 70 patients affected by psoriasis, both genders, older than 18 years. Average age being $47,14(\mathrm{SD}= \pm 15,41)$ years, from that there were 36 men or 51,43 and 34 women or $48,57 \%$. The average duration of psoriasis was $15,52(\mathrm{SD}= \pm 12,54)$ years. For purposes of diagnosing the metabolic syndrome, the criteria of National Cholesterol Education Program Adult Treatment Panel III, (NCEP ATP III) were used. For purposes of detecting the severity and spread of psoriasis, Psoriasis Area and Severity Index (PASI) was used. Results: The incidence of metabolic syndrome in patients with psoriasis was $38,57 \%$. Average values of PASI score were 16,65. The increase in values of PASI score and metabolic syndrome were statistically highly connected. $(\mathrm{r}=0,3, \mathrm{p}=0,0001)$. Conclusion: Psoriasis is connected with metabolic syndrome, there is a positive correlation between the severity of psoriasis and frequency of metabolic syndrome.
\end{abstract}

Key words : psoriasis, metabolic syndrome.

\section{INTRODUCTION}

Psoriasis is a chronic systematic inflammatory disease which is connected with the metabolic syndrome (1). Metabolic syndrome which is also called syndrome of insulin resistance, or syndrome $\mathrm{X}$, is a combination of factors of cardio vascular risk, including central obesity, increased blood pressure, glucose intolerance and dyslipidemia (2). Although the connection between psoriasis and metabolic syndrome is known, what is trying to be discovered is the precise mechanism of that connection, that is, precise pathogen mechanisms. It is considered that a chronic inflammation and inflammatory mediators are the initiators for the development of metabolic syndrome. A term "Psoriasis march" is described where the state of chronic inflammatory in the patient affected by psoriasis leads to insulin resistance, which leads to endothelial dysfunction and atherosclerosis, and consequently to myocardial infarction and stroke (3). In those affected by psoriasis, inflammatory cytokines, TNF, IL-1 and IL-6 are increased (4). They can have a wide specter of effects on insulin signalization, metabolism of lipids and adipogenesis. Besides that, inflammatory induced resistance to insulin can lead to a development of systematic resistance to insulin (5).

Cytokines which are important in pathogenesis of psoriasis IL-1, IL-4, IL-6, IL-8, IL-12 and TNF are also identified in those affected by metabolic syndrome (6). Sim- ilarly to psoriasis, metabolic syndrome is characterized by increase of immunologic activity type 1 of helping $\mathrm{T}$ lymphocytes (7). Next to the inflammation as a common link between these two ailments. PSORS2, PSORS3 and PSORS4 are related to psoriasis and they are also connected with metabolic ailments (4). It is considered that next to the stated role of chronic inflammation, genetic factors also play a role in the development of metabolic syndrome in those affected by psoriasis, a significant role is also played by life style, including improper nutrition, physical inactivity, smoking and consummation of alcohol, stress, which leads to obesity and development of metabolic syndrome $(8,9)$. Importance of metabolic syndrome is also in its frequency in those affected by psoriasis compared to the general population. Many, differently designed studies have shown connection between psoriasis and metabolic syndrome. Compared to the general population, those affected by psoriasis have a higher frequency of metabolic syndrome, and patients with a more severe form of psoriasis have greater odds at developing metabolic syndrome, compared to those with mild psoriasis (10). In USA, patients affected by psoriasis have nearly double prevalence of metabolic syndrome. Based on this data, it is estimated that from 6,6 millions of adults affected by psoriasis, age ranging from 20 to 59 in USA, 2,7 million of them have metabolic syndrome, or nearly a million more people than expected from individuals with- 
out psoriasis (11). The aim of the research is to determine the frequency between metabolic syndrome in those affected by psoriasis, and connection between severity of psoriasis and occurrence of metabolic syndrome.

\section{EXAMINEES AND METHODS}

This prospective research was lead between November of 2011 and June of 2013. It enveloped 70 consecutively chosen patients, affected by psoriasis, both genders, over the age of 18 . Average age being $47,14(\mathrm{SD}= \pm 15,41)$, from that there were 36 men, or $51,43 \%$ and 34 women or $48,57 \%$. Average duration of psoriasis was 15,52 (SD= $\pm 12,54$ ) years. Research also included patients with documented cases of diagnosed psoriasis, ambulatory or hospital reports from dermatologist, and pathophysiological report, of those who were treated at the clinic for skin diseases of University clinical center Tuzla. Research did not include patients which besides psoriasis suffered from some other skin disease, and those which suffered from psoriasis for less than a year. Research has been approved from the side of ethics committee of University clinical center Tuzla. Firstly, all examinees were explained the purpose of the research, asked for a written consent to participate in the research, taken anamnesis, got their skin and visible mucous membranes dermatologically tested and had their PASI score values determined, after which they were subjected to the research, it was established if they suffered from metabolic syndrome. For diagnosing the metabolic syndrome, National Cholesterol Education Program Adult Treatment Panel III (NCEP ATP III) was used, and metabolic syndrome was diagnosed in the presence of 3 or more criteria.

- Central Obesity;

- Waist line (By ethnically affiliation)

- Women $>80 \mathrm{~cm}$

- Men > 94 (for Europe)

- Increased level of triglyceride

- $150 \mathrm{mg} / \mathrm{dl}$ (1,7 mmol/l)

- Or treatment of increased triglycerides

- Lowered HDL-cholesterol

- $\quad<40 \mathrm{mg} / \mathrm{dl}(1,03 \mathrm{mmol} / \mathrm{l})$ in men

- $\quad<50 \mathrm{mg} / \mathrm{dl}(1,29 \mathrm{mmol} / \mathrm{l})$ in women

- Or HDL cholesterol disorder treatment.

- Increased blood pressure.

- Systolic $>130 \mathrm{mmHg}$

- Diastolic $>85 \mathrm{mmHg}$

- Or treatment of previously diagnosed high blood pressure.

- Increased glucose starvation

- Glucose in plasma > 100mg/dl (5,6 mmol/l)

- Or previously diagnosed diabetes type 2 .

For determining the severity and outspread of psoriasis, Psoriasis Area and Severity Index (PASI) was used. In four regions body-head, torso, upper and lower extremities. In the four regions of the body-head, torso, upper and lower extremities evaluated the characteristics of the disease, severity of erythema, infiltration and desquamation with the score 1-4, and the affected area of skin psoriatic changes with the score 1-6 (Table 1). In assessing the severity of erythema scales may not be removed. Theoretically PASI can range from 0-72 (12).
By this method we calculate:

- Buttocks as a part of lower extremities, that is, region of the leg (l)

- Armpits and shoulders as a part of upper extremities, that is, region of the arm (a)

- The neck is calculated as a part of the head (h)

- $\operatorname{Torso}(\mathrm{t})$

For calculating the PASI, the summation of erythemas, infiltrations and desquamations of single region is multiplied with the numerical value of the region of the body and with the percentage by which the lesions have spread at a single region. Results obtained for each single region are calculated in PASI.

\section{Form for calculating PASI:}

PASI $=0,1 x(E h+I h+D h) x A h+0,3 x(E t+I t+D t) x A t+0,2 x-$ $(\mathrm{Ea}+\mathrm{Ia}+\mathrm{Da}) \mathrm{xAa}+0,4 \mathrm{x}(\mathrm{El}+\mathrm{Il}+\mathrm{Dl}) \times \mathrm{Al}$

\begin{tabular}{|c|c|c|c|c|c|c|c|}
\hline Grade & 0 & 1 & 2 & 3 & 4 & 5 & 6 \\
\hline Erythema(E) & \multirow{3}{*}{ None } & \multirow{3}{*}{ Mild } & \multirow{3}{*}{$\begin{array}{l}\text { Medi- } \\
\text { um }\end{array}$} & \multirow{3}{*}{ Strong } & \multirow{3}{*}{$\begin{array}{l}\text { Very } \\
\text { Strong }\end{array}$} & \multirow{3}{*}{ - } & \multirow{3}{*}{-} \\
\hline Infiltration(I) & & & & & & & \\
\hline Desquamation(D) & & & & & & & \\
\hline $\begin{array}{l}\text { Enveloped area of } \\
\text { the skin \% (A) }\end{array}$ & 0 & $1-9$ & $10-29$ & $30-49$ & $50-69$ & $\begin{array}{l}70- \\
89\end{array}$ & $90-100$ \\
\hline
\end{tabular}

\section{Table 1. Measurement of PASI}

Legend: E- Erythema; I-Infiltration; D - Desqumation; A - Area; h-head; t-torso; a -arm; l-leg

For data processing and hypothesis testing was used statistical package Arcus Quickstat Biomedical Version 1.0. Statistical series are described measures of central tendency and variability measures. The relationship between variables was estimated correlation test. As the minimum value of the level of significance was taken as $p<0,05$.

\section{RESULTS}

Frequency of metabolic syndrome in those affected by psoriasis was $38,57 \%$, average age of those affected by metabolic syndrome was 55,84 years. $(S D= \pm 9,61)$, and average duration of basic disease was 19,09 years $(\mathrm{SD}= \pm$ $12,46)$. Clinical characteristics of the patients were estimated based on the index of severity of psoriasis on the affected area (PASI). Average values of the PASI score were 16,65 . Increase in values of PASI score and metabolic syndrome were statistically highly connected. (Figure 1).

\section{DISCUSSION}

Although the exact mechanism of connection between psoriasis and metabolic syndrome is not determined, an increased occurrence in metabolic syndrome in those affected by psoriasis has been detected. Metabolic syndrome which is defined as a presence or treatment of at least three of the following five categories: Increased blood pressure, insulin resistance, lowered HDL cholesterol, hypertriglyceridemia , and central obesity. Frequency of metabolic syndrome depends from the ethnic factors and the set criteria. NCEP ATP III criteria were used in this research. Frequency of metabolic syndrome in this research was $38,57 \%$ and results were similar to those from other studies. More studies have found an increased frequency of metabolic syndrome in those affected by psoriasis, compared to the control group. 


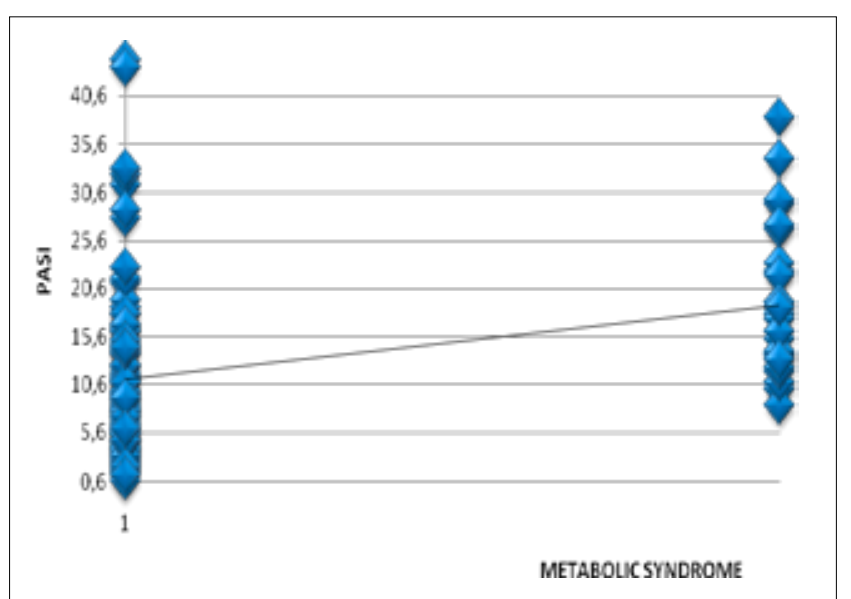

Figure 1. Connection between values of PASI score and metabolic syndrome $(\mathrm{p}=0,0001 ; \mathrm{p}=0,35)$

So in research conducted in India, metabolic syndrome was present in around 30\% of those affected by psoriasis and was around three times more frequent compared to the control group (13). In research conducted in our country, in Mostar, in 60 people affected by psoriasis occurrence of metabolic syndrome was 46,7\% (14).

This research had a positive correlation between the severity of psoriasis, as measured by PASI score and metabolic syndrome $(r=0,35, p=0,0001)$, the higher the PASI, the higher the occurrence of metabolic syndrome. As far the relation between severity of psoriasis and metabolic syndrome, studies have shown different results. In research conducted in Great Britain, which included over 4.000 people affected by psoriasis, Metabolic syndrome was more often present in more severe cases of psoriasis (32\% had a metabolic syndrome with mild psoriasis, 36\% with medium-severe psoriasis and $40 \%$ with severe psoriasis) (15). Also, in a research conducted by Sommer et al. (16), severity of psoriasis was connected with prevalence of metabolic syndrome, that an increased occurrence of metabolic syndrome in the patients with mild and severe form of psoriasis. And in the research conducted in Italy, there was no connection between the severity of psoriasis and occurrence of metabolic syndrome.

Patients with psoriasis and metabolic syndrome were older compared to the average age of all examinees $(55,84$; $\mathrm{SD}= \pm 9,61$ compared to 47,$14 ; \mathrm{SD}= \pm 15,41)$ and they also carried the disease for a somewhat longer period of time 19,0 years $(S D= \pm 12,46)$ compared to the average duration of psoriasis which is 15,52 years $(S D= \pm 12,54)$. In research in Italy, metabolic syndrome was more often present in those affected by psoriasis which were over 40 years of age, and those affected with psoriasis and metabolic syndrome were older and carried psoriasis for a longer period of time compared to those that were affected by psoriasis without metabolic syndrome (17). In a research conducted by Nisa and Qazi (18) metabolic syndrome was found in $28 \%$ of those affected by psoriasis, and in the control group the number was $6 \%$. Those affected by psoriasis with metabolic syndrome had psoriasis for a longer period of time $13,67 \pm 11,87$ years, compared to $6,46 \pm 5,80$ years of those who were affected by psoriasis without metabolic syndrome. In Korea, those affected with psoriasis with metabolic syndrome were older than those af- fected with psoriasis without metabolic syndrome $(53,3$ years compared to 39,5 years, $\mathrm{p}<0,001)$, and they also had a more severe form of the disease, that is, age and severity of the disease were a risk factor for development of metabolic syndrome (19). So, psoriasis is related to metabolic syndrome, and the severity of psoriasis, age, and the length from which the patient has suffered from psoriasis all contributed to the occurrence of metabolic syndrome in those affected by psoriasis.

\section{CONCLUSION}

Psoriasis is connected with metabolic syndrome, and further research of the relation between them is necessary, in the goal of prevention, screening and treatment of metabolic syndrome in those affected by psoriasis.

\section{CONFLICT OF INTEREST: NONE DECLARED.}

\section{REFERENCES}

1. Takahashi H, Iizuka H. Psoriasis and metabolic syndrome. J Dermatol. 2012; 39(3): 212-218.

2. Anonymous. National Cholesterol Education Program (NCEP) Expert Panel on Detection, Evaluation, and Treatment of High Blood Cholesterol in Adults (Adult Treatment Panel III). Third report of the National Cholesterol Education Program (NCEP). Expert Panel on Detection, Evaluation, and Treatment of High Blood Cholesterol in Adults (Adult Treatment Panel III) final report. Circulation. 2002; 106: 3143-3421.

3. Boehncke WH, Boehncke S, Tobin AM, Kirby B. The 'psoriatic march': a concept of how severe psoriasis may drive cardiovascular comorbidity. Exp Dermatol. 2011; 20: 303-307.

4. Azfar R, Gelfand J. Psoriasis and metabolic disease: epidemiology and pathophysiology. Curr Opin Rheumatol. 2008; 20(4): 416-422.

5. Mehta NN, McGillicuddy FC, Anderson PD, Hinkle CC, Shah R, Pruscino $\mathrm{L}$ et al. Experimental endotoxemia induces adipose inflammation and insulin resistance in humans. Diabetes. 2010; 59: 172-181.

6. Kaplan JM. Cardiometabolic risk in psoriasis: differential effects of biologic agents. Vasc Health Risc Manag. 2008; 4(6): 1229-1235.

7. Wysocki J, Skoczynski S, Strozik A, Hochul B, Zygula M. Metabolic or immunometabolic syndrome? Wiad Lek. 2005; 58(1-2): 124-127.

8. Neimann AL, Shin DB, Wang X, Margolis DJ, Troxel AB, Gelfand JM. Prevalence of cardiovascular risk factors in patients with psoriasis. J Am Acad Dermatol. 2006; 55(5): 829-835.

9. Nisa N,Qazi MA. Prevalence of metabolic syndrome in patients with psoriasis.Indian J Dermatol Venereol Leprol. 2010; 76(6): 662-665.

10. Armstrong AW, Harskamp CT, Armstrong EJ. Psoriasis and metabolic syndrome: A systematic review and meta-analysis of observational studies. J Am Acad Dermatol. 2013; 68(4): 654-662.

11. Love TJ, Qureshi AA, Karlson EW, Gelfand JM, Choi HK. Prevalence of the metabolic syndrome in psoriasis: results from the National Health and Nutrition Examination Survey, 2003-2006. Arch Dermatol. 2011; 147(4): 419-424.

12. Fredriksson T, Pettersson U. Severe psoriasis-oral therapy with new retinoid. Dermatologica. 1978; 157: 238-244.

13. Khunger N, Gupta D, Ramesh V. Is psoriasis a new cutaneous marker for metabolic syndrome? A study in Indian patients. Indian J Dermatol. 2013; 58(4): 313-314.

14. Topić I, Šimić D. Prevalence of metabolic syndrome in patients with psoriasis at Mostar Clinical Hospital. Acta Clin Croat. 2013; 52(1): 53-58.

15. Langan SM, Seminara NM, Shin DB, Troxel AB, Kimmel SE, Mehta NN. et al. Prevalence of metabolic syndrome in patients with psoriasis: a population-based study in the United Kingdom. J Invest Dermatol. 2012; 132(3 Pt 1): 556-562.

16. Sommer DM, Jenisch S, Suchan M, Christophers E, Weichenthal M. Increased prevalence of the metabolic syndrome in patients with moderate to severe psoriasis. Archives of Dermatological Research. 2006; 298(7): 321-328.

17. Gisondi P, Tessari G, Conti A, Piaserico S, Schianchi S, Peserico A. et al Prevalence of metabolic syndrome in patients with psoriasis: a hospital-based case-control study. Br J Dermatol. 2007; 157(1): 68-73.

18. Nisa N,Qazi MA. Prevalence of metabolic syndrome in patients with psoriasis. Indian J Dermatol Venereol Leprol. 2010; 76(6): 662-665.

19. Kim GW, Park HJ, Kim HS. Analysis of cardiovascular risk factors and metabolic syndrome in Korean patients with psoriasis. Ann Dermatol. 2012; 24(1): 11-15. 